\title{
Identification and Biochemical Characterization of a Surfactant-Tolerant Chondroitinase VhChlABC from Vibrio hyugaensis LWW-1
}

\author{
Juanjuan Su 1,2,3,4, Xiaoyi Wang 1,2,3,4, Chengying Yin 1,2,3,4, Yujiao Li 1,2,3,4, Hao Wu 1,2,3,4, Wengong Yu 1,2,3,4 \\ and Feng Han $1,2,3,4, *$ (D)
}

1 School of Medicine and Pharmacy, Ocean University of China, 5 Yushan Road, Qingdao 266003, China; sujuanjuan@stu.ouc.edu.cn (J.S.); wangxiaoyi@stu.ouc.edu.cn (X.W.); yinchengying@stu.ouc.edu.cn (C.Y.); lyj6476@stu.ouc.edu.cn (Y.L.); wuhao1330@stu.ouc.edu.cn (H.W.); yuwg66@ouc.edu.cn (W.Y.)

2 Laboratory for Marine Drugs and Bioproducts of Qingdao National Laboratory for Marine Science and Technology, 1 Wenhai Road, Qingdao 266237, China

3 Key Laboratory of Marine Drugs, Ministry of Education, 5 Yushan Road, Qingdao 266003, China

4 Shandong Provincial Key Laboratory of Glycoscience and Glycotechnology, 5 Yushan Road, Qingdao 266003, China

* Correspondence: fhan@ouc.edu.cn; Tel.: +86-532-8203-2067

check for updates

Citation: Su, J.; Wang, X.; Yin, C.; Li, Y.; Wu, H.; Yu, W.; Han, F.

Identification and Biochemical

Characterization of a

Surfactant-Tolerant Chondroitinase VhChlABC from Vibrio hyugaensis LWW-1. Mar. Drugs 2021, 19, 399. https://doi.org/10.3390/md19070399

Academic Editors: Antonio Trincone and Claudiu T. Supuran

Received: 17 June 2021

Accepted: 16 July 2021

Published: 18 July 2021

Publisher's Note: MDPI stays neutral with regard to jurisdictional claims in published maps and institutional affiliations.

Copyright: (C) 2021 by the authors. Licensee MDPI, Basel, Switzerland. This article is an open access article distributed under the terms and conditions of the Creative Commons Attribution (CC BY) license (https:/ / creativecommons.org/licenses/by/ $4.0 /)$.
Abstract: Chondroitinases, catalyzing the degradation of chondroitin sulfate (CS) into oligosaccharides, not only play a crucial role in understanding the structure and function of CS, but also have been reported as a potential candidate drug for the treatment of high CS-related diseases. Here, a marine bacterium Vibrio hyugaensis LWW-1 was isolated, and its genome was sequenced and annotated. A chondroitinase, VhChlABC, was found to belong to the second subfamily of polysaccharide lyase (PL) family 8 . VhChlABC was recombinant expressed and characterized. It could specifically degrade CS-A, CS-B, and CS-C, and reached the maximum activity at $\mathrm{pH} 7.0$ and $40{ }^{\circ} \mathrm{C}$ in the presence of $0.25 \mathrm{M} \mathrm{NaCl}$. VhChlABC showed high stability within $8 \mathrm{~h}$ under $37^{\circ} \mathrm{C}$ and within $2 \mathrm{~h}$ under $40^{\circ} \mathrm{C}$. VhChlABC was stable in a wide range of $\mathrm{pH}(5.0 \sim 10.6)$ at $4{ }^{\circ} \mathrm{C}$. Unlike most chondroitinases, VhChlABC showed high surfactant tolerance, which might provide a good tool for removing extracellular CS proteoglycans (CSPGs) of lung cancer under the stress of pulmonary surfactant. VhChlABC completely degraded CS to disaccharide by the exolytic mode. This research expanded the research and application system of chondroitinases.

Keywords: chondroitinases; surfactant tolerance; chondroitin sulfate

\section{Introduction}

Chondroitin sulfate (CS), a kind of glycosaminoglycan that can covalently link with protein to form proteoglycan, is widely distributed in the extracellular matrix and cell surface of animal tissues [1,2]. CS plays an important regulatory role in many physiological processes such as cell development, cell adhesion, proliferation and differentiations [3-7]. Commercially important applications of CS in biological tissue engineering have been explored, which involve combining it with other biopolymers to form scaffolds capable of facilitating and accelerating the regeneration of damaged structures [3].

The CS chain is made up of disaccharide units consisting of D-glucuronic acid (GlcUA)/L-iduronic acid (IdoUA) linked to N-acetyl-D-galactosamine (GalNAc) and sulfated at the $\mathrm{C} 2$ position of uronic acid and/or at the C4/C6 position of GalNAc residue [8]. Although the structure of the main chain of polysaccharides is not complex, it shows a high degree of heterogeneity in terms of the degree of sulfation, the sulfation position, and the distribution of the two kinds of different isoguronic acids within the chain. Existing studies have indicated the interaction effect between CS and various growth factors/adhesion 
in numerous important physiological events [8-12]. However, due to the lack of understanding of the fine structure of CS, its functional specificity and interactions with various proteins have been only meagerly explored [5]. Moreover, although CS proteoglycans (CSPGs) are necessary for normal body function, abnormal levels of CSPGs are associated with numerous debilitating conditions [13]. Chondroitinase is mainly used in the pathological condition of increased CSPGs. It can degrade CSPGs to reduce their inhibitory effect on axonal sprouting and functional recovery after spinal cord injury [14]. Another potentially important therapeutic application of chondroitinase is in visual therapy, where it has been shown to induce plasticity in the visual cortex by degrading the deposited CSPGs through animal experiments $[15,16]$. In addition, the promotion effect of CS on tumor genesis, growth, and metastasis can be neutralized by chondroitinase to a certain extent $[17,18]$. These all make the chondroitinase indispensable for both structure-function decipherment of CS and deepness development to medicinal value.

Bacteria-derived CS lyases catalyze the degradation of CS via $\beta$-elimination reaction, triggering the breaking of $1 \rightarrow 4$ glycosidic bonds between hexosamine and uronic acid residues, and finally forming 4, 5-unsaturated double bonds at the non-reducing end. CS lyases (CSases) can be divided into four classes, CSase ABC, CSase AC, CSase B, and CSase $\mathrm{C}$, according to their substrate specificity. They can also be classified as endo- or exo-type based on the degradation mode [19]. Among these types, the broad catalytic activity of CSase ABCs against CS and hyaluronic acid (HA) determines its crucial applications in both structure-function study and the treatment for many diseases $[13,20,21]$. However, only a few CSase ABCs derived from bacteria of Proteus [19,22], Bacteroides [23], Acinetobacter [24], and Sphingomonas [25] have been identified. The limitation in activity and stability of CSase $\mathrm{ABC}$ s have also greatly limited its application. Therefore, it is urgent for both basic research and application to identify more CSase $\mathrm{ABC}$ s with better properties.

In this study, a new CSase $A B C$, named VhChlABC, was identified from the marine bacterium Vibrio hyugaensis LWW-1. The main properties and some factors interfering with catalytic reaction of VhChlABC were investigated in detail. With specific degradation for $\mathrm{CS}$, broad tolerance range of $\mathrm{pH}$, and high tolerance to surfactant, VhChlABC might provide a useful tool for CS-related researches and application.

\section{Results and Discussion}

\subsection{Identification of Strain LWW-1}

The 16S rDNA of strain LWW-1 was sequenced and submitted to the 16S-based EzBioCloud's identification service. Per the results, strain LWW-1 showed the highest similarity of 99.64\% with the Vibrio hyugaensis strain 090810a (Accession Number: LC004912). Therefore, strain LWW-1 was identified as V. hyugaensis.

\subsection{Identification and Sequence Analysis of CS-Degrading Enzyme}

The vhchlABC gene (GenBank number: MZ173502) encoding a chondroitin lyase was identified by sequencing the genome of strain LWW-1. It was $3081 \mathrm{bp}$ in length and encoded a 1026-amino-acid protein, including a signal peptide $\left(\mathrm{Met}^{1}-\mathrm{Asn}^{24}\right)$ at the $\mathrm{N}$-terminus. The theoretical molecular weight of $\mathrm{VhChlABC}$ was $114.1 \mathrm{kDa}$, and the theoretical isoelectric point was 5.59. A conserved GAG lyase domain $\left(\mathrm{Ala}^{244}-\mathrm{Pro}^{941}\right.$ ) was predicted in VhChlABC.

Similarity analysis indicated that VhChlABC was a member of the PL-8 family, with the highest identity of $82.05 \%$ to the characterized HCDase (GenBank number: ALJ56196.1) from Vibrio sp. FC509 [26]. A phylogenetic tree was drawn based on the amino acid sequences of VhChlABC and other characterized members of the PL-8 family. As a result, VhChlABC was assigned to the second subfamily (Figure 1). The amino acid alignment of VhChlABC and the identified PL8 family enzymes showed that VhChlABC contained the conserved catalytic residues of the PL8 family in $\mathrm{His}^{484}, \mathrm{Tyr}^{491}$, and $\mathrm{Arg}^{544}$ (Figure A1 in Appendix B). 

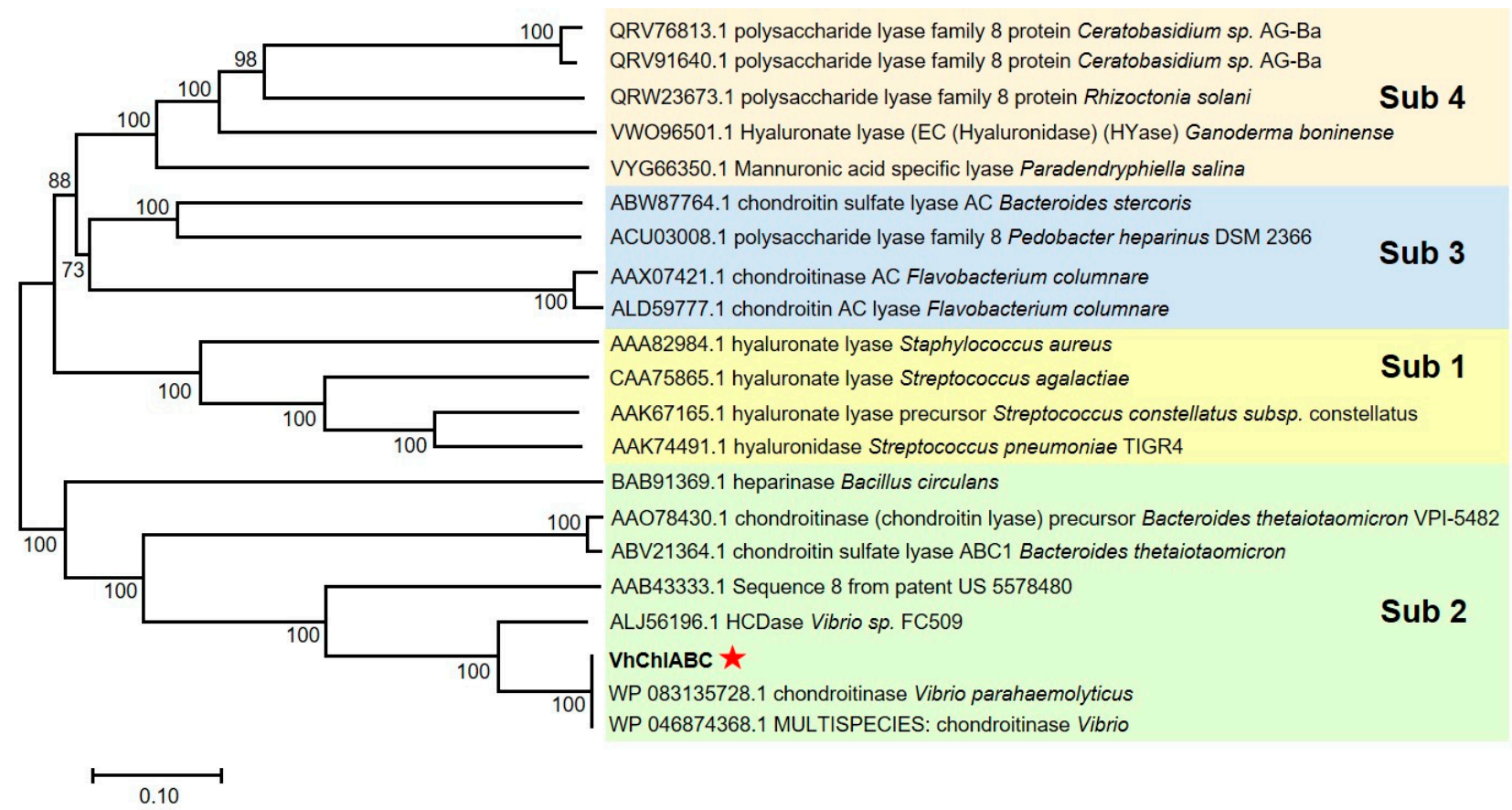

Figure 1. Phylogenetic tree of VhChlABC and other members of PL8. Amino acid sequences were used for this analysis. The numbers (0 100) on the branches indicate the reliability of the corresponding branches. A larger value means more reliable. Sub, subfamily.

\subsection{Recombinant Expression and Purification of VhChlABC}

The gene vhchlABC was cloned into the vector pET-28a (+) with removal of the signal peptide and addition of (His) 6 -Tag at both ends. VhChlABC was expressed in soluble forms in the pET-28a (+)/E.coli BL21 (DE3) system. The recombinant VhChlABC was obtained from $40 \mathrm{~mL}$ of the bacteria lysate supernatant through nickel affinity chromatography. As shown in Figure 2, a main band (estimated purity $>90 \%$ ) in SDS-PAGE with a molecular weight of about $110 \mathrm{kDa}$ was identified. The specific activity of purified VhChlABC towards CS-A was $17.54 \mathrm{U} / \mathrm{mg}$. The protein recovery was $16.69 \%$ during purification, and about $9.25 \mathrm{mg}$ of purified VhChlABC could be obtained from $1 \mathrm{~L}$ of bacterial fermentation broth (Table 1).

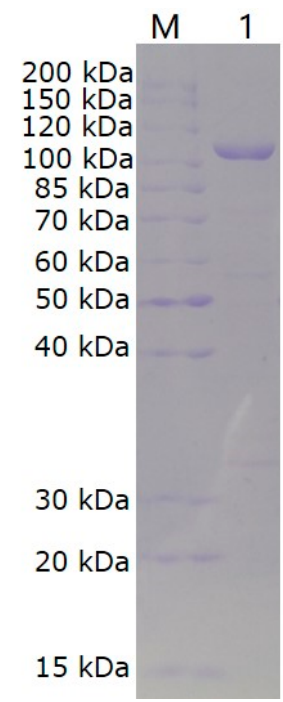

Figure 2. SDS-PAGE of VhChlABC. Lane M, protein marker; lane 1, purified VhChlABC. 
Table 1. Summary of the purified VhChlABC.

\begin{tabular}{cccccc}
\hline Step & $\begin{array}{c}\text { Specific Activity } \\
(\mathbf{U} / \mathbf{m g})\end{array}$ & $\begin{array}{c}\text { Total Protein } \\
(\mathbf{m g})\end{array}$ & $\begin{array}{c}\text { Total Activity } \\
(\mathbf{U})\end{array}$ & $\begin{array}{c}\text { Fold Purification } \\
\mathbf{( \% )}\end{array}$ \\
\hline Fermentation broth & 3.66 & 106.22 & 388.77 & 1 & 100 \\
Nickel column & 17.54 & 3.70 & 64.90 & 4.79 & 16.69 \\
\hline
\end{tabular}

The $\mathrm{A}_{232}$ method was used for this detection. Enzyme activity was measured using $0.2 \% \mathrm{CS}-\mathrm{A}$ as substrate (20 mM PB, $\left.\mathrm{pH} 7.0\right)$ under optimal conditions. The volume of the initial fermentation broth was $400 \mathrm{~mL}$, and the volume of the concentrated crude extract was $40 \mathrm{~mL}$.

\subsection{Substrate Specificity of VhChlABC}

The substrate specificity of VhChlABC was determined using a variety of glycolaminoglycans as substrates. As shown in Figure 3, VhChlABC could only degrade CS-A, CS-B, and CS-C, but showed no activity towards other tested substrates. VhChlABC showed the highest degradation activity towards CS-A, and the lowest towards CS-C, which was more than $60 \%$ of the former. The specific activity towards CS-A and CS-B was similar. Among the three kinds of CS, VhChlABC possessed the highest $k_{\text {cat }} / K_{m}$ value on CS-A at $1.83 \mathrm{~min}^{-1} \cdot \mathrm{mM}^{-1}$, followed by CS-C and CS-B (Table 2 ).

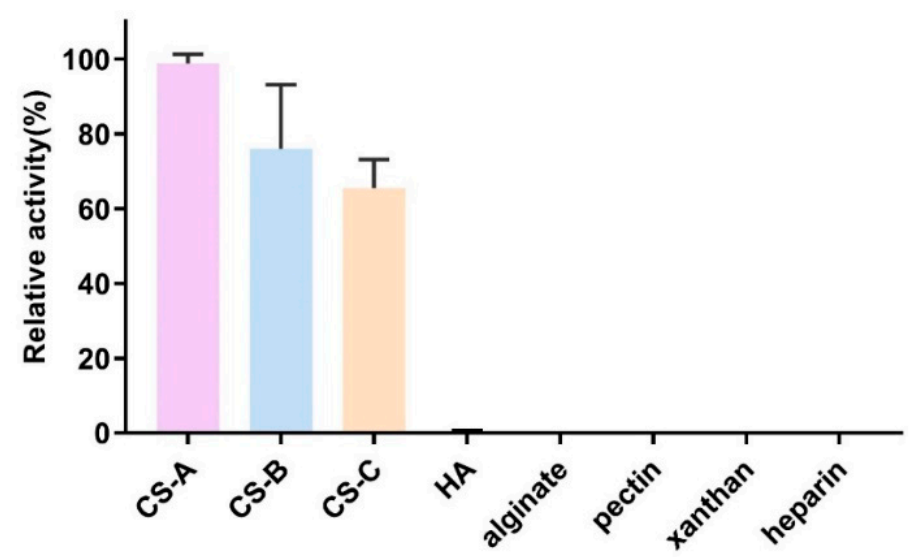

Figure 3. Substrate specificity of VhChlABC. The activity of VhChlABC towards CS-A was defined as $100 \%$. Error bars indicate standard deviation $(n=3)$.

Table 2. $K_{m}, k_{\text {cat }}$, and $V_{\max }$ values of VhChlABC.

\begin{tabular}{ccccc}
\hline Substrate & $\begin{array}{c}\boldsymbol{K}_{\boldsymbol{m}} \\
(\boldsymbol{\mu M})\end{array}$ & $\begin{array}{c}\boldsymbol{V}_{\max } \\
(\boldsymbol{\mu \mathbf { m o l } \cdot \mathbf { m i n }}-\mathbf{1})\end{array}$ & $\begin{array}{c}\boldsymbol{k}_{\text {cat }} \\
\left(\mathbf{m i n}^{-1}\right)\end{array}$ & $\begin{array}{c}\boldsymbol{k}_{\text {cat }} / \boldsymbol{K}_{\boldsymbol{m}} \\
\left(\mathbf{m i n}^{-\mathbf{1}} \cdot \mathbf{m M}^{-\mathbf{1})}\right.\end{array}$ \\
\hline CS-A & $2.90 \pm 0.35$ & $1.06 \pm 0.04$ & $5310 \pm 200$ & $1.83 \pm 0.069$ \\
CS-B & $4.29 \pm 0.33$ & $0.90 \pm 0.02$ & $4468 \pm 123$ & $1.04 \pm 0.029$ \\
CS-C & $2.67 \pm 0.22$ & $0.70 \pm 0.01$ & $3465 \pm 72$ & $1.30 \pm 0.027$ \\
\hline
\end{tabular}

Most reported bacteria-derived CSase $\mathrm{ABC}$ exhibit a wide range of degrading activity against HA and CS, such as HCDase and HCLase from Vibrio sp. FC509 [26,27], chondroitin sulfate ABC lyase (EC 4.2.2.20) from Bacteroides thetaiotaomicron WAL2926 [23], ChSase ABC from Acinetobacter sp. C26 [24], ChSase ABC from Sphingomonas paucimobilis [25], and chondroitinase ABC I and chondroitinase ABC II (EC 4.2.2.20) from Proteus vulgaris et al. [19,22]. Unlike these, VhChlABC could degrade CS but not HA, which was also found in the study of ChABC I and ChABC II from Edwardsiella tarda LMG2793 and of chondroitin $\mathrm{ABC}$ from Bacteroides stercoris [28,29].

\subsection{Effects of Temperature and $p H$ on VhChlABC}

According to the results of an optimal temperature test, VhChlABC exhibited the highest activity towards CS-A at $40{ }^{\circ} \mathrm{C}$ (Figure 4a), which was similar to most members of PL-8 family, such as ChSase ABC from Bacteroides stercoris and Sphingomonas paucimobilis or 
ChSase AC from Flavobacterium heparinum et al. $[25,29,30]$. Thermostability testing indicated that after pre-incubation at a temperature below $30^{\circ} \mathrm{C}$ for $1 \mathrm{~h}$, VhChlABC remained about $90 \%$ of its initial activity (Figure $4 \mathrm{~b}$ ). After pre-incubation at $40{ }^{\circ} \mathrm{C}$ for $1 \mathrm{~h}$ (Figure $4 \mathrm{~b}$ ), the activity retained was more than $60 \%$, and it was approximately $50 \%$ after pre-incubation for $2 \mathrm{~h}$ (Figure 4c). However, the activity decreased rapidly when the pre-incubation temperature was higher than $40^{\circ} \mathrm{C}$ (Figure $4 \mathrm{~b}$ ). Furthermore, after incubation for more than $2 \mathrm{~h}$ at $40^{\circ} \mathrm{C}$, the activity of VhChlABC decreased rapidly and was almost lost until $6 \mathrm{~h}$ (Figure 4c). After treatment at $37^{\circ} \mathrm{C}$ for $8 \mathrm{~h}$, VhChlABC could retain about $50 \%$ of its initial activity; however, the activity reduced rapidly and was almost lost after $12 \mathrm{~h}$ (Figure $4 \mathrm{c}$ ). In fact, poor thermostability has become an important limiting factor for the application of CS lyases. As reported, CABC I and CABC II from Proteus vulgaris NCTC 4636 cannot maintain $50 \%$ of their activity after treatment at $40{ }^{\circ} \mathrm{C}$ for $30 \mathrm{~min}$ [31]. As for HCDase from Vibrio sp. FC509, its activity gradually declined to $20 \%$ after treatment at $30^{\circ} \mathrm{C}$ for $4 \mathrm{~h}$ [26]. In this research, VhChlABC presented higher stability within $8 \mathrm{~h}$ under $37^{\circ} \mathrm{C}$ (physiological temperature) and within $2 \mathrm{~h}$ under $40^{\circ} \mathrm{C}$ (optimal temperature), which might contribute to CS-related clinical application and industrial production.
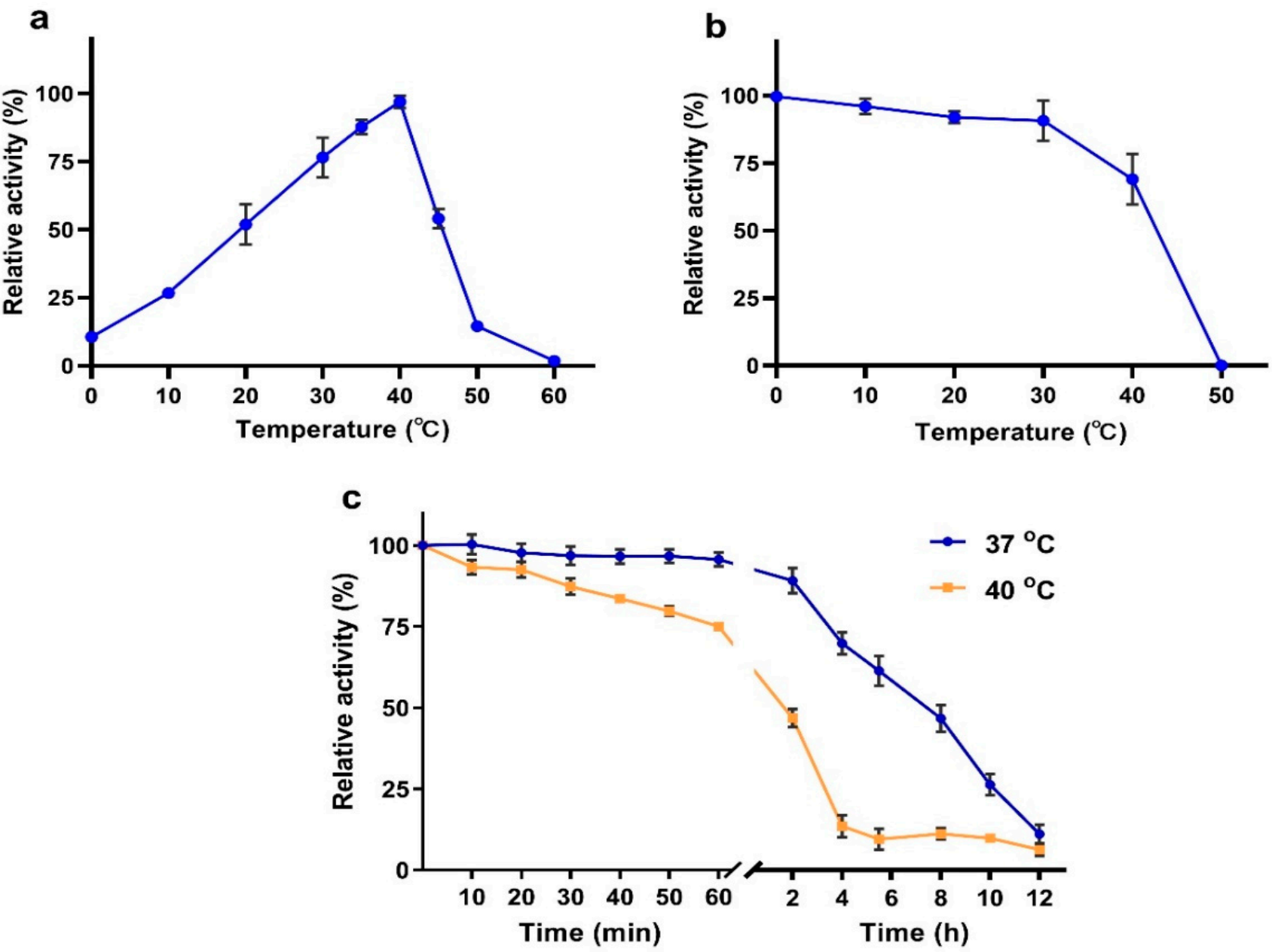

Figure 4. Effects of temperature on VhChlABC. (a) Optimal temperature of VhChlABC. (b,c) The thermostability of VhChlABC. (b) The residual activity of VhChlABC was measured after pre-incubation at different temperatures $\left(0 \sim 50{ }^{\circ} \mathrm{C}\right)$ for $1 \mathrm{~h}$. (c) The residual activity of $\mathrm{VhChlABC}$ was detected at different timepoints after incubation at $37^{\circ} \mathrm{C}$ and $40^{\circ} \mathrm{C}$. The initial activity was defined as $100 \%$. Error bars indicated standard deviation $(n=3)$. 
The optimal $\mathrm{pH}$ value for the degradation activity of VhChlABC against CS-A was pH 7.0 in $50 \mathrm{mM} \mathrm{Na}_{2} \mathrm{HPO}_{4}-\mathrm{NaH}_{2} \mathrm{PO}_{4}$ buffer (Figure 5a). Moreover, VhChlABC could keep stable in different buffers of $\mathrm{pH}$ 5.0 10.6 (Figure 5b). With the high stability on $\mathrm{pH}$, VhChlABC might be easier to preserve and more widely used in the industry.


Figure 5. Effects of $\mathrm{pH}$ on VhChlABC. (a) Optimal pH of VhChlABC. (b) pH stability of VhChlABC. CS-A was used as the substrate. The activity of VhChlABC at the optimal $\mathrm{pH}$ and temperature was defined as $100 \%$. Error bars indicated standard deviation $(n=3)$.

\subsection{Effects of Metal Ions, Chelators, and Surfactants on VhChlABC}

As shown in Figure 6a, no tested metal ions enhanced the CS degradation activity of VhChlABC significantly. $\mathrm{Zn}^{2+}, \mathrm{Co}^{2+}$, and $\mathrm{Ni}^{2+}$ could strongly inhibit its activity, which was consistent with Vibrio sp. FC509 HCDase and HCLase-related results [26,27]. The structural changes caused by the affinity of heavy metals towards the $\mathrm{SH}, \mathrm{CO}$, and $\mathrm{NH}$ groups in the amino acids might be the crucial factor for the inhibition of VhChlABC by metal ions such as $\mathrm{Zn}^{2+}$ [32]. In addition, differences of amino acids on the protein surface might also be important for the metal ion effect [33], which might result in the different effects of metal ions on HCDase, HCLase, and VhChlABC. Additionally, $\mathrm{NaCl}$ enhanced the CS-degradation activity of VhChlABC at low concentrations $(\leq 0.25 \mathrm{M})$ and exhibited the maximum effect at $0.25 \mathrm{M}$ (Figure 6b). Notably, even if there was no $\mathrm{NaCl}$ in the reaction system, VhChlABC still maintained nearly $50 \%$ of its maximum activity (Figure $6 \mathrm{~b}$ ), which indicated that $\mathrm{VhChlABC}$ had no dependency on $\mathrm{NaCl}$ and could satisfy more $\mathrm{NaCl}$-limited production conditions.

In particular, VhChlABC well tolerated both SDS and Tween-20, maintaining more than $50 \%$ of its maximum activity in the presence of up to $10 \%(w / v)$ SDS and having almost no loss of activity in the presence of up to 10\% $(v / v)$ Tween-20 (Figure 6c). Although research has continued to report glycosaminoglycanases (GAGases) of novel structures and functions, studies on surfactant-tolerant GAGases are almost nonexistent. Besides being used as detergents in daily life, other applications of surfactants could cover almost all fine chemical fields [34]. Unfortunately, most of the reported GAGases were inactivated in the presence of very low concentrations of SDS. As reported, SDS could almost completely inhibit the activity of enCSase from Photobacterium sp. QA16 [20], Vpa_0049 from Vibrio sp. QY108 [35], and ChSase ABC from Acinetobacter sp. C26 [24], with final concentrations of $5 \mathrm{mM}, 1 \mathrm{mM}$, and $5 \mathrm{mM}$, respectively. Unfortunately, the surfactant tolerance of many enzymes has not been measured, including HCDase from Vibrio sp. FC509. The crucial domains and key amino acid residues that determine the surfactant tolerance of VhChlABC must be further explored. 
a

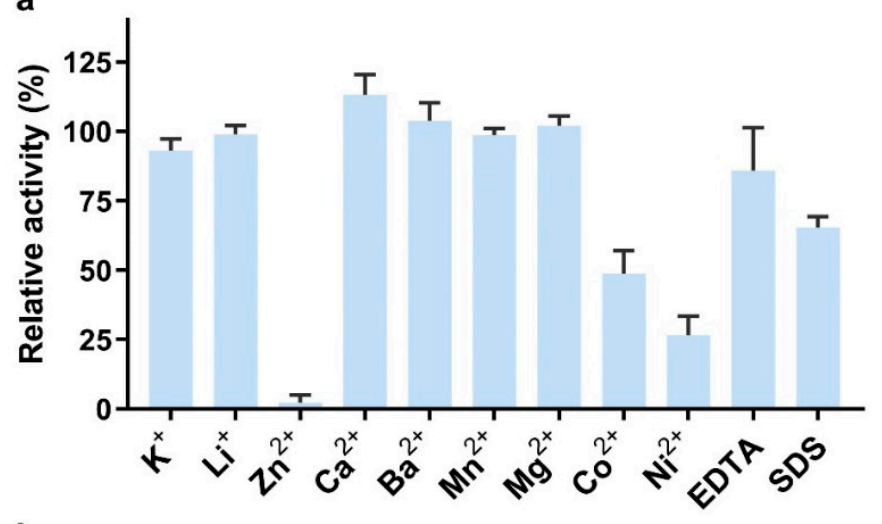

b
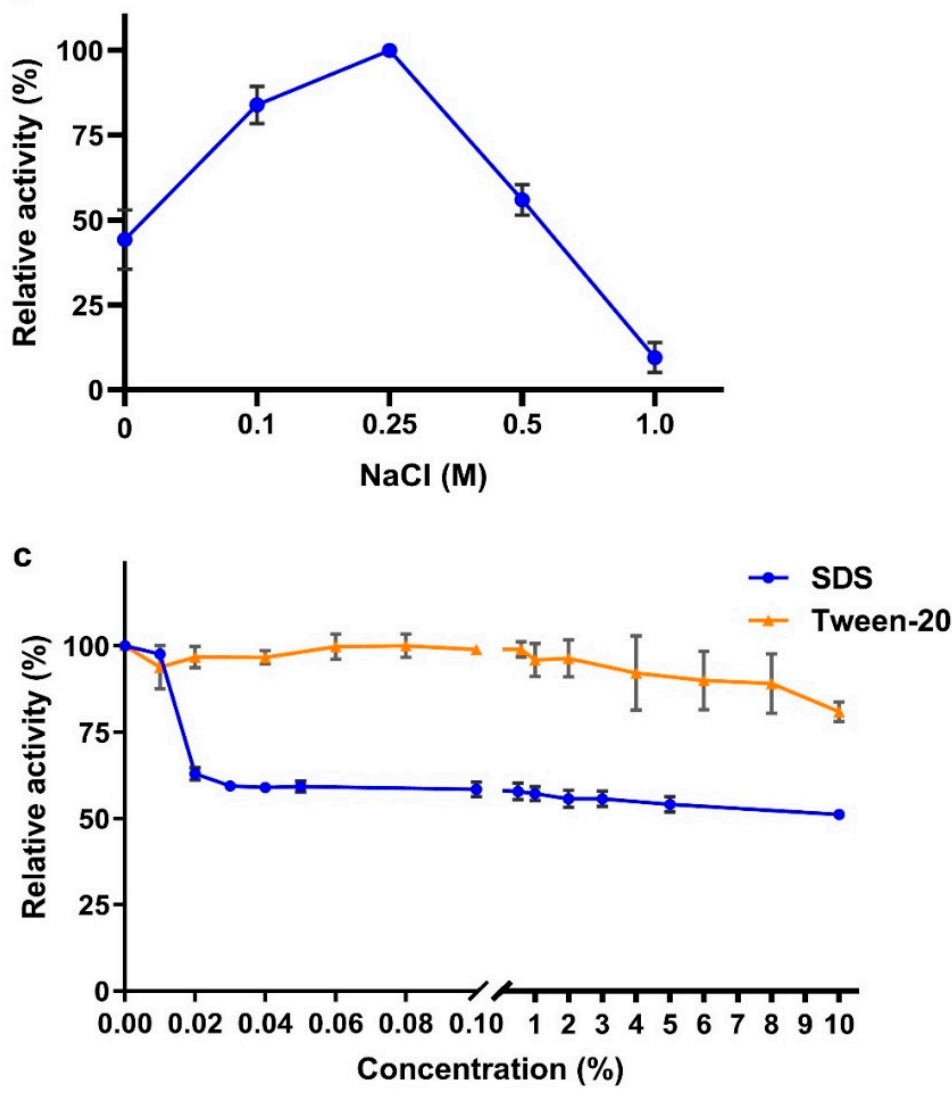

Figure 6. Effects of metal ions, chelators, and detergents on the activity of VhChlABC. (a) Effects of metal ions, chelator $(1 \mathrm{mM})$, and surfactant (SDS, $0.1 \%, w / v)$. (b) Effects of $\mathrm{NaCl}$ concentrations $(0 \sim 1 \mathrm{M}) .(\mathbf{c})$ Effects of SDS and Tween-20. Error bars indicated standard deviation $(n=3)$.

It was considered a safe and effective strategy to remove extracellular CS proteoglycans (CSPGs) using chondroitinase, which was reported to promote viral spread and infection in oncolytic virus (OV)-mediated treatment of astrocytomas [36]. However, the sensitivity of chondroitinase to trace surfactants might limit its application in the lung environment under the stress of pulmonary surfactant. Therefore, the high surfactant tolerance of VhChlABC might open a new horizon for the treatment of lung cancer. In addition, Vibrio is widely distributed in different water bodies and marine animals, has strong vitality, and has been recognized as an important pathogen in the aquaculture industry [37]. The identification of the surfactant-tolerance gene vhchlABC is of great significance for understanding the stress tolerance mechanism of Vibrio. 


\subsection{Degradation Mode and End Products of VhChlABC}

SEC was performed to analyze the degradation modes and end products of CS-A, CS-B, and CS-C by VhChlABC. Per the results, only one major product peak was detected during the reaction (Figure 7a), indicating that VhChlABC degraded CS through the exolytic mode, which was consistent with HCDase [26]. All the enzymatic properties suggested that VhChlABC was an EC 4.4.2.21—chondroitin-sulfate-ABC exolyase. The end products of CS-A, CS-B, and CS-C were all identified as the same single peak (data not shown), with a molecular weight of $458.06 \mathrm{~m} / \mathrm{z}(z=1)$ identified by negative-ion ESI-MS (Figure $\mathrm{7b}$ ). It was consistent with the $\mathrm{m} / \mathrm{z}$ of unsaturated monosulfated disaccharides of CS-A $\left([\Delta \mathrm{Di} 4 \mathrm{~S}-\mathrm{H}]^{-}\right), \mathrm{CS}-\mathrm{B}\left([\Delta \mathrm{Di} 4 \mathrm{~S}-\mathrm{H}]^{-}\right)$, and CS-C $\left([\Delta \mathrm{Di} 6 \mathrm{~S}-\mathrm{H}]^{-}\right)[25,35]$. These results indicated that VhChlABC could completely degrade CS to unsaturated disaccharides through the exolytic mode.
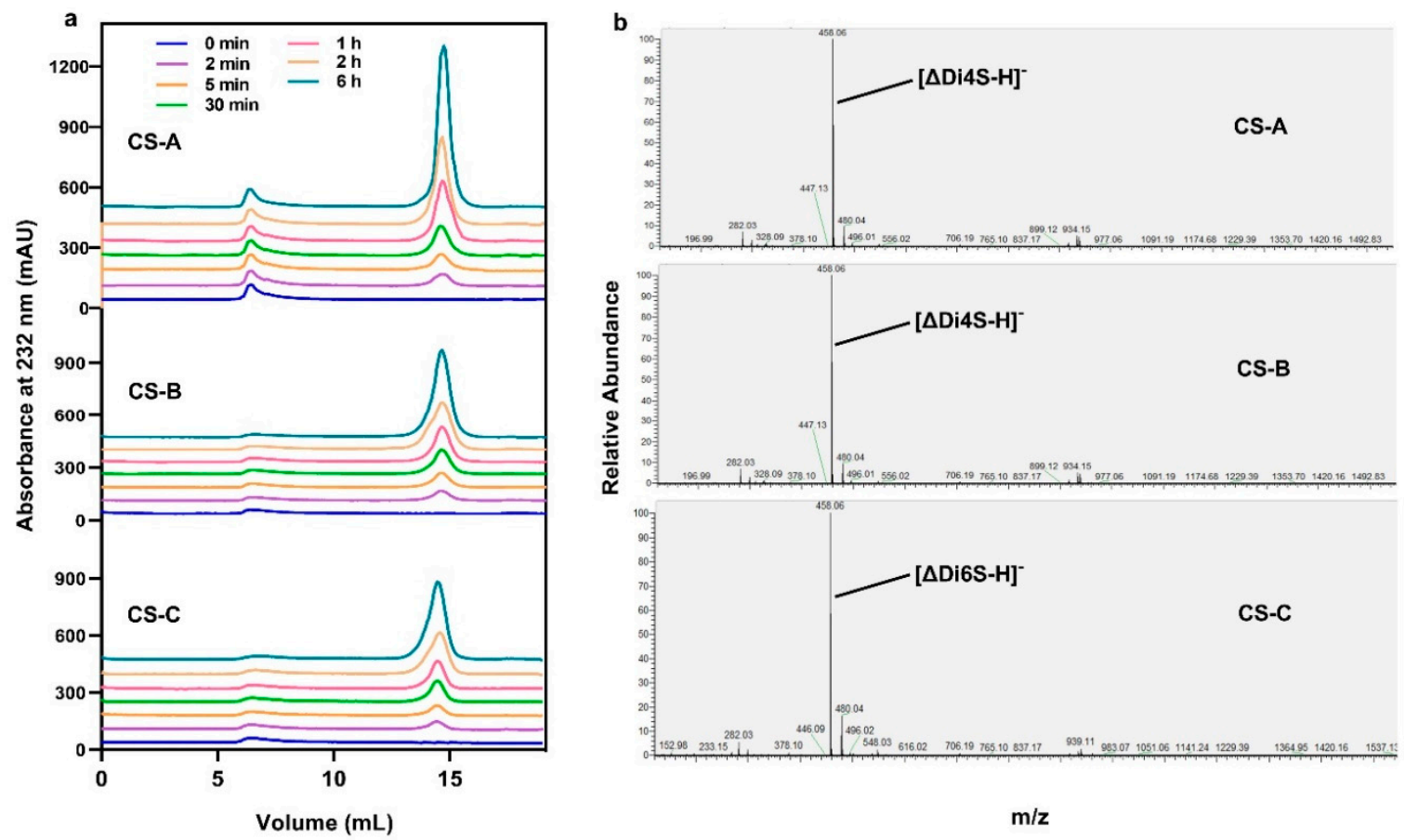

Figure 7. The reaction modes and end products of CS-A, CS-B, and CS-C degraded by VhChlABC. (a) The time courses of CS-A, CS-B, and CS-C degradation by VhChlABC. (b) ESI-MS analysis of the end products.

\section{Materials and Methods}

\subsection{Reagents}

Phanta max super-fidelity DNA polymerase (P505-d1) was purchased from Vazyme (Nanjing, China). Takara quick-cut enzyme and T4 DNA ligase kit were purchased from Biomedical Technology Co., Ltd. (Beijing, China). Chondroitin sulfate A (CS-A), CS-B, and CS-C were purchased from Hefei Bomei Biotechnology Co., Ltd. (Hefei, China). HA, alginate, pectin, xanthan, and heparin were purchased from Solarbio (Beijing, China). TIANamp bacteria DNA kit (Tiangen, China) was used to extract the bacterial genome. HisTrap HP column and Superdex Peptide 10/300 GL was purchased from GE Healthcare (Pittsburgh, PA, USA).

\subsection{Isolation of Marine CS Lyase-Producing Bacteria}

Seawater sample was collected from Zhanqiao, QingDao, China. A selective medium, which consisted of $0.3 \%(w / v) \mathrm{KH}_{2} \mathrm{PO}_{4}, 0.7 \%(w / v) \mathrm{K}_{2} \mathrm{HPO}_{4} \cdot 3 \mathrm{H}_{2} \mathrm{O}, 0.2 \%(w / v)\left(\mathrm{NH}_{4}\right)_{2} \mathrm{SO}_{4}$, $0.01 \%(w / v) \mathrm{FeSO}_{4} \cdot 7 \mathrm{H}_{2} \mathrm{O}, 3 \% \mathrm{NaCl}, 0.05 \%(w / v) \mathrm{CS}$ (CS-A: CS-B: CS-C $=1: 1: 1$ by mass), and $1.5 \%(w / v)$ agar $(\mathrm{pH} 7.0)$, was used to isolate CS lyase-producing bacteria from the seawater sample. Obviously, CS was the sole carbon source. The screening model referred 
to the Gram's iodine plate assay method for hyaluronidase [38]. Briefly, after pre-incubation at $25^{\circ} \mathrm{C}$ for $48 \mathrm{~h}$, the plates containing the microorganisms were soaked with Gram's iodine for $1 \mathrm{~min}$. Clones with distinct clearance zones were detected as CS-degrading strains and then purified with fresh selective medium plates three times to obtain the pure cultured strains. Then, the pure monoclonal strains were cultured in $100 \mathrm{~mL}$ marine broth 2216 at $25^{\circ} \mathrm{C}$ and $160 \mathrm{rpm} / \mathrm{min}$ for $48 \mathrm{~h}$, and the CS lyase activity in the culture supernatant was determined using the $A_{232}$ method (as shown in Section 3.6). The strain LWW-1, which exhibited the highest CS lyase activity, was obtained and used in the following experiment.

\subsection{Identification of Strain LWW-1}

The $16 \mathrm{~S}$ rDNA of strain LWW-1 was amplified by PCR with the universal primer pairs 27F (5'-AGAGTTTGATCCTGGCTCAG-3') -1492R (5'-TACGGTTACCTTGTTACGACTT$\left.3^{\prime}\right)$, using a colony strain as the template. After purification, the PCR product was then sequenced by Ruibiotech Co., Ltd. (Beijing, China). The isolated strain LWW-1 was identified using $16 \mathrm{~S}$ rDNA sequence using the EzBioCloud's identification service (https: / / www.ezbiocloud.net accessed on 15 November 2020).

\subsection{Sequence Analysis of VhChlABC}

The genomic DNA of strain LWW-1 was prepared using Tianamp bacteria DNA kit. The genome of strain LWW-1 was sequenced by Novogene Bioinformatics Technology Co., Ltd. (Beijing, China) and then annotated with Rapid Annotation using Subsystem Technology (RAST). Sequence similarity analysis was performed by online BLAST. The phylogenetic tree was drawn using the neighbor-joining method by MEGA 7.1. The molecular weight $(\mathrm{Mw})$ and isoelectric point $(\mathrm{pI})$ were analyzed by the compute $\mathrm{Mw} / \mathrm{pI}$ tool on ExPASy of Swiss Bioinformatics Resource Portal (http:/ / us.expasy.org/tools/pi tool.html accessed on 15 November 2020). The SignalP 5.0 server (http:/ / www.cbs.dtu.dk/ services/SignalP / accessed on 15 November 2020) was used to predict the signal peptide and its cleavage site in VhChlABC. The protein domains within VhChlABC were identified using the Conserved Domains server of NCBI database (http:/ / www.ncbi.nlm.nih.gov/ Structure/cdd/wrpsb.cgi accessed on 15 November 2020). Amino acid alignment with other enzymes of the PL8 family was carried out using ESPrit 3.0 (https:/ / espript.ibcp.fr/ ESPript/ESPript/ accessed on 15 November 2020).

\subsection{Recombinant Expression and Purification of VhChlABC}

The full-length gene of $v$ hchl$A B C$ without the signal peptide sequence was amplified with super-fidelity DNA polymerase (Vazyme, Nanjing, China) and the primer pairs ChlABC-F (GTACcatatgAGCGAAAATGTTGAAAGCA) and ChlABC-R (GTACctcgagTACTTTTTTCAGCATGAATTTT), taking the genomic DNA of $V$. hyugaensis LWW-1 as the template. After digestion with Nde I and Xho I, the gel-recovered PCR products were ligated into plasmid pET-28a (+). Then, the plasmid pET-28a-VhChlABC was transformed into $E$. coli BL21 (DE3) cells to obtain the recombinant expression strains.

The recombinant expression strains were cultured in Luria-Bertani (LB) medium (containing $30 \mu \mathrm{g} / \mathrm{mL}$ kanamycin) with shaking at $37^{\circ} \mathrm{C}$ until the $\mathrm{OD}_{600}$ value reached $0.4 \sim 0.6$. Then, it was induced to express VhChlABC by adding $0.1 \mathrm{mM}$ isopropyl-1thio- $\beta$-D-galactoside (IPTG) and incubated at $18{ }^{\circ} \mathrm{C}$ for $24 \mathrm{~h}$. After centrifugation with $8000 \mathrm{rpm} / \mathrm{min}$ for $30 \mathrm{~min}$ at $4{ }^{\circ} \mathrm{C}$, cells were resuspended in precooled $20 \mathrm{mM}$ phosphate buffer (PB) containing $500 \mathrm{mM} \mathrm{NaCl}$ at $\mathrm{pH} 7.0$ (binding buffer) at a volume of $1 / 10$ of the initial fermentation broth, then ruptured by the high-pressure cell cracker at $4{ }^{\circ} \mathrm{C}$. Next, the supernatant (usually named crude extract) containing the soluble target protein was collected by centrifugation at $12,000 \mathrm{rpm} / \mathrm{min}$ for $30 \mathrm{~min}$. The crude extract was subsequently filled by a constant current pump onto a Ni-Sepharose column (GE Healthcare, Pittsburgh, PA, USA) pre-balanced with binding buffer. The (His) ${ }_{6}$-tagged VhChlABC protein was eluted from the column using binding buffer with $300 \mathrm{mM}$ imidazole added. The molecular weight and purity of VhChlABC were examined by SDS-PAGE combined with Coomassie 
Bright Blue staining. Protein content was measured according to the instructions of BCA protein assay kit (EpiZyme, Shanghai, China).

\subsection{Enzyme Activity Determination of VhChlABC}

In this study, two methods were used to determine the enzyme activity. As for the $\mathrm{A}_{232}$ method [28], a reaction system containing $100 \mu \mathrm{L}$ of enzyme sample, which in turn contained approximately $1.0 \mu \mathrm{g}$ of purified VhChlABC, and $900 \mu \mathrm{L}$ of $0.2 \%(w / v) \mathrm{CS}$ substrate was incubated at $40{ }^{\circ} \mathrm{C}$ for $10 \mathrm{~min}$. The change of absorbance value at $232 \mathrm{~nm}$ was measured to quantify the unsaturated double bonds in the system. One unit (U) was defined as the amount of enzyme required to catalyze the production of $1 \mu \mathrm{mol}$ of 4,5-unsaturated uronic acid per minute. The millimolar absorption coefficients for CS-A, CS-B, and CS-C were 5.1, 5.1, and 5.5 respectively [39].

As for the DNS (dinitrosalicylic acid) method [40], $50 \mu \mathrm{L}$ of enzyme sample, which contained approximately $3.0 \mu \mathrm{g}$ of purified VhChlABC, and $450 \mu \mathrm{L}$ of $0.2 \%(w / v) \mathrm{CS}$ substrate $(20 \mathrm{mM} \mathrm{PB}, \mathrm{pH} 7.0)$ were co-incubated at $40{ }^{\circ} \mathrm{C}$ for $10 \mathrm{~min}$. After that, $375 \mu \mathrm{L}$ of DNS reagent, prepared as described in Appendix A, was added to the system and boiled at $100{ }^{\circ} \mathrm{C}$ for $10 \mathrm{~min}$. Then, the reducing sugar content was quantified by measuring the absorbance value of the reaction solution at $520 \mathrm{~nm}$ using D-glucosamine as a standard. For both methods, the same reaction with an equal amount of enzyme, inactivated by boiling for $10 \mathrm{~min}$, was used as the blank. One unit was defined as the amount of enzyme that generated reducing sugars corresponding to $1 \mu \mathrm{mol}$ of glucosaminehydrochloride per minute under standard conditions.

\subsection{Substrates Specificity Analysis of VhChlABC}

Various commercial polysaccharide substrates at $0.2 \%(w / v)$, including HA, CS-A, CS$\mathrm{B}, \mathrm{CS}-\mathrm{C}$, alginate, pectin, xanthan and heparin $(20 \mathrm{mM} \mathrm{PB}, \mathrm{pH} 7.0)$, were used as substrates to determine the substrate specificity of VhChlABC. $A_{232}$ method was used for this test under optimal conditions.

\subsection{Biochemical Characterization of VhChlABC}

Biochemical characterization was determined using CS-A as the substrate. The $\mathrm{A}_{232}$ method was used for this test. For optimum temperature detection, $0.2 \%(w / v)$ CS-A (20 mM PB, pH 7.0) was digested by VhChlABC at a serial temperature gradient from 0 to $60{ }^{\circ} \mathrm{C}$. To determine the thermostability, VhChlABC was pre-incubated at different temperatures $\left(0 \sim 50{ }^{\circ} \mathrm{C}\right)$ for $1 \mathrm{~h}$, and the residual activity was measured at $40^{\circ} \mathrm{C}$. Furthermore, the residual activity of $\mathrm{VhChlABC}$ was examined at different times post incubation at $37^{\circ} \mathrm{C}$ and $40{ }^{\circ} \mathrm{C}$. The initial specific activity detected at $40^{\circ} \mathrm{C}$ was set as $100 \%$.

For optimum $\mathrm{pH}$ detection, the activity of $\mathrm{VhChlABC}$ was analyzed under different $\mathrm{pH}$ buffers of $50 \mathrm{mM}$ at $40{ }^{\circ} \mathrm{C}$, including $\mathrm{Na}_{2} \mathrm{HPO}_{4}-\mathrm{NaH}_{2} \mathrm{PO}_{4}$ with $\mathrm{pH}$ of $6.0 \sim 8.0$, Tris- $\mathrm{HCl}$ with $\mathrm{pH}$ of 7.05 8.95, $\mathrm{NaH}_{2} \mathrm{PO} 4$-citric acid with $\mathrm{pH}$ of 3.0 8.0, and glycine- $\mathrm{NaOH}$ with $\mathrm{pH}$ of 8.6 10.6. To analyze the effect of $\mathrm{pH}$ on stability, VhChlABC was incubated in a series of $\mathrm{pH}$ buffers at $4^{\circ} \mathrm{C}$ for $12 \mathrm{~h}$, respectively. Then, residual activity was measured by the $\mathrm{A}_{232}$ method under optimal conditions.

Different ions, including $\mathrm{K}^{+}, \mathrm{Li}^{+}, \mathrm{Zn}^{2+}, \mathrm{Ca}^{2+}, \mathrm{Ba}^{2+}, \mathrm{Mn}^{2+}, \mathrm{Mg}^{2+}, \mathrm{Co}^{2+}$, and $\mathrm{Ni}^{2+}$, and chelator (EDTA) were separately added to the reaction mixture at a final concentration of 1 $\mathrm{mM}$ to detect their effect on $\mathrm{CS}$ degradation by VhChlABC. $\mathrm{NaCl}$ dependence might be the specificity of marine active enzymes; therefore, the effects of $\mathrm{NaCl}$ concentrations $(0 \sim 1.0 \mathrm{M})$ on the activity of VhChlABC were detected in this research. The $A_{232}$ method was used for the above detection under optimal conditions. The effects of SDS and Tween-20 on VhChlABC were detected by adding different final concentrations of SDS $(0 \sim 10 \%, w / v)$ and Tween-20 $(0 \sim 10 \%, v / v)$ separately into the reaction system. SDS and Tween-20 can greatly increase the absorbance of the substrate at $232 \mathrm{~nm}$, which is beyond the reliable range of the $\mathrm{A}_{232}$ method. Therefore, the DNS method was used for this detection. 


\subsection{Reaction Kinetics of VhChlABC towards CS}

CS-A, CS-B, and CS-C were each dissolved in $20 \mathrm{mM} \mathrm{PB} \mathrm{(pH} \mathrm{7.0)} \mathrm{to} \mathrm{prepare} \mathrm{substrates}$ with concentrations from 0.2 to $2.0 \mathrm{mg} / \mathrm{mL}$. The absorbance value of the enzyme-substrate (1:9 by vol) reaction system at $232 \mathrm{~nm}$ was measured after incubation at $40^{\circ} \mathrm{C}$ for $3 \mathrm{~min}$. $V_{\max }$ and $K_{m}$ values were calculated using the Michaelis-Menten equation and the curve fitting program by the non-linear regression analysis using Graphpad Prism 8. The $k_{c a t}$ value was the ratio of $V_{\max }$ to the enzyme concentration.

\subsection{Reaction Mode and End Products of VhChlABC}

The reaction modes of VhChlABC towards CS-A, CS-B, and CS-C were monitored. Degradation reaction was initiated by uniformly mixing enzyme and substrate $(20 \mathrm{mM}$ $\mathrm{PB}, \mathrm{pH}$ 7.0) in proper proportions under optimal conditions and terminated by boiling at different timepoints. The unsaturated oligosaccharide products with different degrees of polymerization in the samples of different timepoints were separated and analyzed by size-exclusion chromatography (SEC). Fast protein liquid chromatography (FPLC, GE Healthcare, Pittsburgh, PA, USA) combined with a Superdex peptide 10/300 GL column (GE Healthcare, Pittsburgh, PA, USA) was used for this process. For the mobile phase, $0.2 \mathrm{M} \mathrm{NH}_{4} \mathrm{HCO}_{3}$ at a flow rate of $0.2 \mathrm{~mL} / \mathrm{min}$ was used. The absorbance value at $232 \mathrm{~nm}$ was monitored.

Moreover, $0.5 \mathrm{~mL}$ CS-A/CS-B/CS-C $(0.2 \%, w / v, 20 \mathrm{mM} \mathrm{PB}, \mathrm{pH} 7.0)$ was co-incubated with $0.5 \mathrm{~mL}$ purified $\mathrm{VhChlABC}$ (containing approximately $20 \mu \mathrm{g}$ of purified $\mathrm{VhChlABC}$ ) at $40{ }^{\circ} \mathrm{C}$ for $24 \mathrm{~h}$. The end-products were detected and separated by SEC, then further identified by negative-ion electrospray ionization-mass spectrometry (ESI-MS).

\section{Conclusions}

In this study, a novel PL-8 chondroitin sulfate lyase, VhChlABC, was identified and characterized from marine bacterium $V$. hyugaensis LWW-1. Although VhChlABC has the highest amino acid identify (82.05\%) with HCDase, it possesses some significantly different characteristics from the latter. The discovery of surfactant-tolerant chondroitinase provides a new way for the treatment of CS-related diseases in special pathological conditions. The wider $\mathrm{pH}$ tolerance range makes $\mathrm{VhChlABC}$ a potentially good enzymatic tool in industry application without rigorous reaction and storage conditions.

Author Contributions: Conceptualization, J.S., X.W., F.H., and W.Y.; data curation, J.S. and Y.L.; formal analysis, C.Y. and H.W.; funding acquisition, F.H. and W.Y.; investigation, J.S., X.W., C.Y., Y.L., and H.W.; supervision, F.H. and W.Y.; writing—original draft, J.S.; writing—review and editing, F.H. All authors have read and agreed to the published version of the manuscript.

Funding: This research was funded by National Key R\&D Program of China (2018YFC0311105), Natural Science Foundation of Shandong Province (ZR2019ZD18), Marine S\&T Fund of Shandong Province for Pilot National Laboratory for Marine Science and Technology (Qingdao) (2018SDKJ04012), and National Science and Technology Major Project for Significant New Drugs Development (2018ZX09735004).

Conflicts of Interest: The authors declare no conflict of interest.

\section{Appendix A}

Preparation method of DNS reagent. 1. Preparation of solutions A and B. Solution A: $6.9 \mathrm{~g}$ crystalline phenol was dissolved in $15.2 \mathrm{~mL}$ of $10 \% \mathrm{NaOH}$ solution and diluted to $69 \mathrm{~mL}$ with water, and then $6.9 \mathrm{~g} \mathrm{NaHSO}_{3}$ was added. Solution B: $255 \mathrm{~g} \mathrm{NaKC}_{4} \mathrm{H}_{4} \mathrm{O}_{6} \cdot 4 \mathrm{H}_{2} \mathrm{O}$ was dissolved in $200 \mathrm{~mL}$ of $10 \% \mathrm{NaOH}$ solution, and then $880 \mathrm{~mL}$ of $1 \%$ DNS solution was added. 2. Mix solutions A and B and allow the reagent to stand for 7 to 10 days at room temperature before use. 


\section{Appendix B}

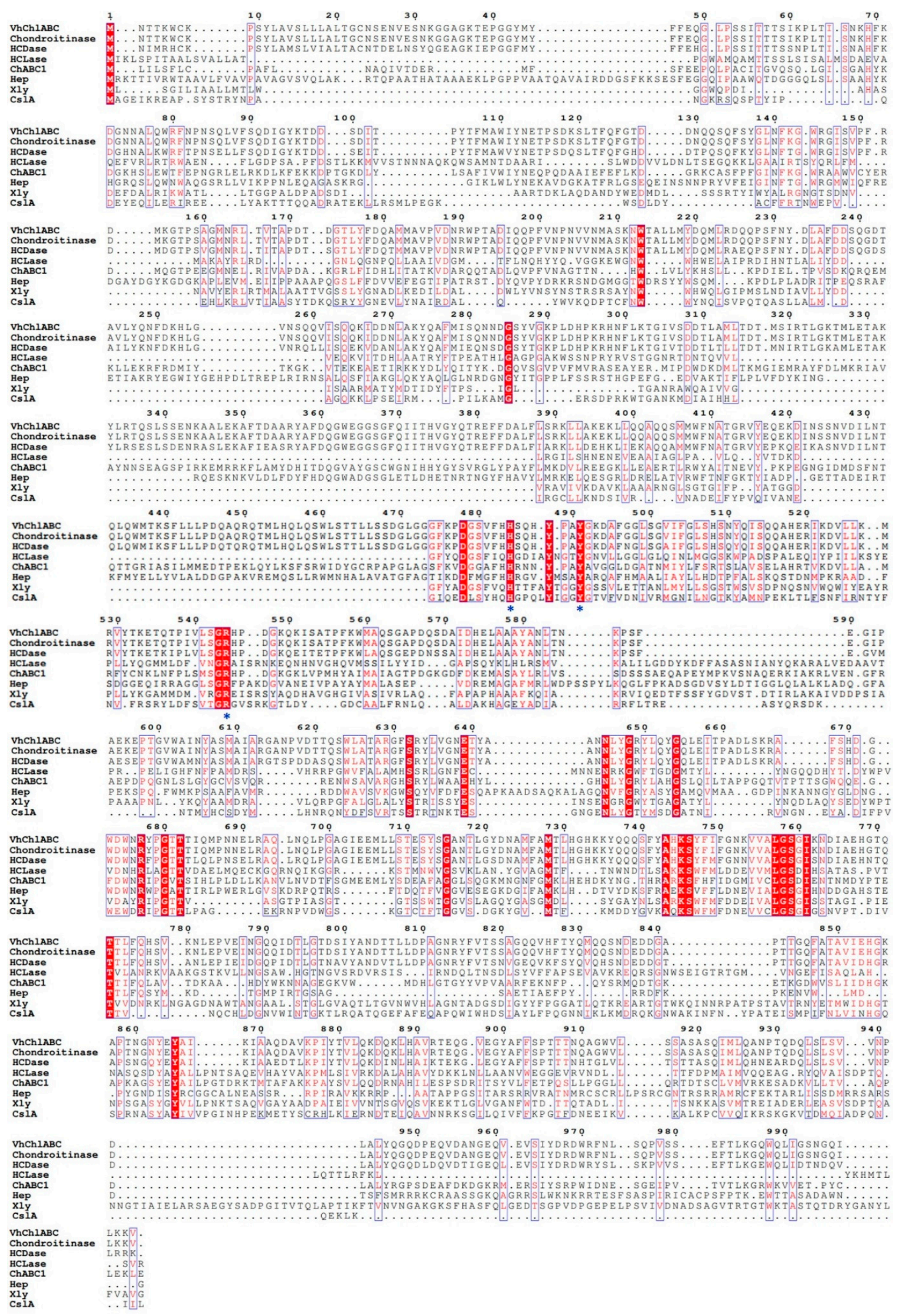

Figure A1. Protein sequence alignment of VhChlABC to the identified enzymes of the PL8 family. Red backgrounds 
represent the same amino acid residues, and blue frames indicate amino acid residues with identity $>70 \%$. The critical catalytic residues were highlighted by asterisks below them. Chondroitinase, from Vibrio parahaemolyticus, GenBank number: WP_083135728; HCDase, from Vibrio sp. FC509, GenBank number: ALJ56196.1; HCLase, from Vibrio sp. FC509, GenBank number: AIL54323.1; ChABC1, from Bacteroides thetaiotaomicron WAL2926, GenBank number: ABV21364.1; Hep, from Bacillus circulans, GenBank number: BAB91369.1; Xly, from Bacillus sp. GL1, GenBank number: BAB21059.1; CslA, from Bacteroides stercoris HJ-15, GenBank number: ABW87764.1.

\section{References}

1. Kreuger, J.; Spillmann, D.; Li, J.P.; Lindahl, U. Interactions between heparan sulfate and proteins: The concept of specificity. J. Cell Biol. 2006, 174, 323-327. [CrossRef]

2. Ly, M.; Laremore, T.N.; Linhardt, R.J. Proteoglycomics: Recent progress and future challenges. Omics 2010, 14, 389-399. [CrossRef] [PubMed]

3. Bishnoi, M.; Jain, A.; Hurkat, P.; Jain, S.K. Chondroitin sulphate: A focus on osteoarthritis. Glycoconj. J. 2016, 33, 693-705. [CrossRef] [PubMed]

4. Sugahara, K.; Kitagawa, H. Recent advances in the study of the biosynthesis and functions of sulfated glycosaminoglycans. Curr. Opin. Struct. Biol. 2000, 10, 518-527. [CrossRef]

5. Mikami, T.; Kitagawa, H. Biosynthesis and function of chondroitin sulfate. Biochim. Biophys. Acta 2013, 1830, 4719-4733. [CrossRef]

6. Trowbridge, J.M.; Rudisill, J.A.; Ron, D.; Gallo, R.L. Dermatan sulfate binds and potentiates activity of keratinocyte growth factor (FGF-7). J. Biol. Chem. 2002, 277, 42815-42820. [CrossRef] [PubMed]

7. Nandi, S.; Akhter, M.P.; Seifert, M.F.; Dai, X.M.; Stanley, E.R. Developmental and functional significance of the CSF-1 proteoglycan chondroitin sulfate chain. Blood 2006, 107, 786-795. [CrossRef]

8. Sugahara, K.; Mikami, T.; Uyama, T.; Mizuguchi, S.; Nomura, K.; Kitagawa, H. Recent advances in the structural biology of chondroitin sulfate and dermatan sulfate. Curr. Opin. Struct. Biol. 2003, 13, 612-620. [CrossRef]

9. Rani, A.; Patel, S.; Goyal, A. Chondroitin Sulfate (CS) Lyases: Structure, Function and Application in Therapeutics. Curr. Protein Pept. Sci. 2018, 19, 22-33. [CrossRef]

10. Rauch, U.; Kappler, J. Chondroitin/Dermatan sulfates in the central nervous system: Their structures and functions in health and disease. Adv. Pharmacol. 2006, 53, 337-356.

11. Shioiri, T.; Tsuchimoto, J.; Watanabe, H.; Sugiura, N. Sequence determination of synthesized chondroitin sulfate dodecasaccharides. Glycobiology 2016, 26, 592-606. [CrossRef]

12. Clement, A.M.; Nadanaka, S.; Masayama, K.; Mandl, C.; Sugahara, K.; Faissner, A. The DSD-1 carbohydrate epitope depends on sulfation, correlates with chondroitin sulfate D motifs, and is sufficient to promote neurite outgrowth. J. Biol. Chem. 1998, 273, 28444-28453. [CrossRef] [PubMed]

13. Kasinathan, N.; Volety, S.M.; Josyula, V.R. Chondroitinase: A promising therapeutic enzyme. Crit. Rev. Microbiol. 2016, 42, 474-484. [CrossRef]

14. Rosenzweig, E.S.; Salegio, E.A.; Liang, J.J.; Weber, J.L.; Weinholtz, C.A.; Brock, J.H.; Moseanko, R.; Hawbecker, S.; Pender, R.; Cruzen, C.L.; et al. Chondroitinase improves anatomical and functional outcomes after primate spinal cord injury. Nat. Neurosci. 2019, 22, 1269-1275. [CrossRef] [PubMed]

15. Pizzorusso, T.; Medini, P.; Berardi, N.; Chierzi, S.; Fawcett, J.W.; Maffei, L. Reactivation of ocular dominance plasticity in the adult visual cortex. Science 2002, 298, 1248-1251. [CrossRef]

16. Vorobyov, V.; Kwok, J.C.; Fawcett, J.W.; Sengpiel, F. Effects of digesting chondroitin sulfate proteoglycans on plasticity in cat primary visual cortex. J. Neurosci. 2013, 33, 234-243. [CrossRef]

17. Wegrowski, Y.; Maquart, F.X. Chondroitin sulfate proteoglycans in tumor progression. Adv. Pharmacol. $2006,53,297-321$.

18. Denholm, E.M.; Lin, Y.Q.; Silver, P.J. Anti-tumor activities of chondroitinase AC and chondroitinase B: Inhibition of angiogenesis, proliferation and invasion. Eur. J. Pharmacol. 2001, 416, 213-221. [CrossRef]

19. Prabhakar, V.; Capila, I.; Soundararajan, V.; Raman, R.; Sasisekharan, R. Recombinant expression, purification, and biochemical characterization of chondroitinase ABC II from Proteus vulgaris. J. Biol. Chem. 2009, 284, 974-982. [CrossRef]

20. Zhang, Q.; Lu, D.; Wang, S.; Wei, L.; Wang, W.; Li, F. Identification and biochemical characterization of a novel chondroitin sulfate/dermantan sulfate lyase from Photobacterium sp. Int. J. Biol. Macromol. 2020, 165, 2314-2325. [CrossRef] [PubMed]

21. Muir, E.; De Winter, F.; Verhaagen, J.; Fawcett, J. Recent advances in the therapeutic uses of chondroitinase ABC. Exp. Neurol. 2019, 321, 113032. [CrossRef]

22. Prabhakar, V.; Capila, I.; Bosques, C.J.; Pojasek, K.; Sasisekharan, R. Chondroitinase ABC I from Proteus vulgaris: Cloning, recombinant expression and active site identification. Biochem. J. 2005, 386, 103-112. [CrossRef]

23. Shaya, D.; Hahn, B.S.; Park, N.Y.; Sim, J.S.; Kim, Y.S.; Cygler, M. Characterization of chondroitin sulfate lyase ABC from Bacteroides thetaiotaomicron WAL2926. Biochemistry 2008, 47, 6650-6661. [CrossRef] [PubMed]

24. Zhu, C.; Zhang, J.; Zhang, J.; Jiang, Y.; Shen, Z.; Guan, H.; Jiang, X. Purification and characterization of chondroitinase ABC from Acinetobacter sp. C26. Int. J. Biol. Macromol. 2017, 95, 80-86. [CrossRef] [PubMed] 
25. Fu, J.; Jiang, Z.; Chang, J.; Han, B.; Liu, W.; Peng, Y. Purification, characterization of Chondroitinase ABC from Sphingomonas paucimobilis and in vitro cardiocytoprotection of the enzymatically degraded CS-A. Int. J. Biol. Macromol. 2018, 115, 737-745. [CrossRef]

26. Wang, W.; Cai, X.; Han, N.; Han, W.; Sugahara, K.; Li, F. Sequencing of chondroitin sulfate oligosaccharides using a novel exolyase from a marine bacterium that degrades hyaluronan and chondroitin sulfate/dermatan sulfate. Biochem. J. 2017, 474, 3831-3848. [CrossRef]

27. Han, W.; Wang, W.; Zhao, M.; Sugahara, K.; Li, F. A novel eliminase from a marine bacterium that degrades hyaluronan and chondroitin sulfate. J. Biol. Chem. 2014, 289, 27886-27898. [CrossRef]

28. Song, G.; Sun, J.; Zhao, M.; Wang, Z.; Gong, Q.; Yu, W. Cloning and characterization of two chondroitin sulfate ABC lyases from Edwardsiella tarda LMG2793. Enzym. Microb. Technol. 2021, 143, 109701. [CrossRef]

29. Hong, S.W.; Kim, B.T.; Shin, H.Y.; Kim, W.S.; Lee, K.S.; Kim, Y.S.; Kim, D.H. Purification and characterization of novel chondroitin ABC and AC lyases from Bacteroides stercoris HJ-15, a human intestinal anaerobic bacterium. Eur. J. Biochem. 2002, 269, 2934-2940. [CrossRef] [PubMed]

30. Gu, K.; Linhardt, R.J.; Laliberté, M.; Gu, K.; Zimmermann, J. Purification, characterization and specificity of chondroitin lyases and glycuronidase from Flavobacterium heparinum. Biochem. J. 1995, 312 Pt 2, 569-577. [CrossRef]

31. Hamai, A.; Hashimoto, N.; Mochizuki, H.; Kato, F.; Makiguchi, Y.; Horie, K.; Suzuki, S. Two distinct chondroitin sulfate ABC lyases. An endoeliminase yielding tetrasaccharides and an exoeliminase preferentially acting on oligosaccharides. J. Biol. Chem. 1997, 272, 9123-9130. [CrossRef] [PubMed]

32. Oh, C.; Nikapitiya, C.; Lee, Y.; Whang, I.; Kim, S.J.; Kang, D.H.; Lee, J. Cloning, purification and biochemical characterization of beta agarase from the marine bacterium Pseudoalteromonas sp. AG4. J. Ind. Microbiol. Biotechnol. 2010, 37, 483-494. [CrossRef] [PubMed]

33. Bulut, H.; Valjakka, J.; Yuksel, B.; Yilmazer, B.; Turunen, O.; Binay, B. Effect of Metal Ions on the Activity of Ten NAD-Dependent Formate Dehydrogenases. Protein J. 2020, 39, 519-530. [CrossRef]

34. Jimoh, A.A.; Lin, J. Biosurfactant: A new frontier for greener technology and environmental sustainability. Ecotoxicol. Environ. Saf. 2019, 184, 109607. [CrossRef] [PubMed]

35. Zhang, Z.; Su, H.; Wang, X.; Tang, L.; Hu, J.; Yu, W.; Han, F. Cloning and characterization of a novel chondroitinase ABC categorized into a new subfamily of Polysacch. lyase family 8. Int. J. Biol. Macromol. 2020, 164, 3762-3770. [CrossRef]

36. Dmitrieva, N.; Yu, L.; Viapiano, M.; Cripe, T.P.; Chiocca, E.A.; Glorioso, J.C.; Kaur, B. Chondroitinase ABC I-mediated enhancement of oncolytic virus spread and antitumor efficacy. Clin. Cancer Res. 2011, 17, 1362-1372. [CrossRef]

37. Li, L.; Meng, H.; Gu, D.; Li, Y.; Jia, M. Molecular mechanisms of Vibrio parahaemolyticus pathogenesis. Microbiol. Res. 2019, 222, 43-51. [CrossRef]

38. Patil, S.; Chaudhari, B. A simple, rapid and sensitive plate assay for detection of microbial hyaluronidase activity. J. Basic Microbiol. 2017, 57, 358-361. [CrossRef]

39. Yamagata, T.; Saito, H.; Habuchi, O.; Suzuki, S. Purification and properties of bacterial chondroitinases and chondrosulfatases. J. Biol. Chem. 1968, 243, 1523-1535. [CrossRef]

40. Han, Y.; Yu, R.; Gao, P.; Lu, X.; Yu, W. The hydrogen-bond network around Glu160 contributes to the structural stability of chitosanase CsnA from Renibacterium sp. QD1. Int. J. Biol. Macromol. 2018, 109, 880-887. [CrossRef] 